\title{
Developing Effective Study Programmes for Public Administrators
}

\section{Ron Goslin}

To provide study and training programmes closely attuned to the identified needs of administrators in developing countries remains both a recurrent goal and also an elusive ideal for host organisations. When staff attempt to examine the precise tasks inherent in the process of needs identification and the implications for programme development, it soon becomes evident that such an approach abounds with contaminants.

Programme planners base their designs upon needs voiced in a variety of ways-those communicated by potential participants; those provided by actual participants prior to their arrival, or on arrival, or during the programme. Some may select intakes for pre-established programmes. A quite different procedure may be to obtain guidance and information from participants' sponsors or employers, although it clearly does not follow that needs identified by either participant or employer are accurate. Attempts are often made to modify existing programmes to accord with data fed back to the design team from evaluation procedures. In all these approaches to needs, in relation to design, undue emphasis may be placed on the programme, its components and contents; this results in a shift away from the individual participant towards a subject analysis. From such a viewpoint, staff designing programmes may well be tempted, or feel required, to assert what administrators in the various public services need as a core of public administration studies and competences. It is likely that most organisations and centres offering programmes will, in their preparation, pursue and utilise an admixture of methods in needs determination, as already outlined. Moreover the focus and pattern will be influenced by situational constraints, the work style of programme directors and their support staff, the requirements and procedures of funding agents and other intermediary agents through which the host body and programme intakes are brought together. Staff with particular responsibilities for evaluating programme achievements will be aware that, though actual needs for study and training must exist, the isolation of such needs from contaminants which distort, conceal or otherwise influence them is a difficult process.
Political, institutional, career and personal factors are clearly significant.

Even if intake needs can be satisfactorily established, to proceed to provide appropriate programmes will inevitably involve the use of some organisational body charged with the task of policy formulation and review, to which the organisation looks for leadership in programme planning, and even their control and management. It is necessary to assimilate new ventures into the existing pattern of programmes provided by the organisation. From the initial stage of identifying needs for a new programme, a sequence of events and decision situations is encountered in each of which the provision of a tailor-made model is challenged, or at least subject to conflicting influences.

Let us suppose that composite needs have been formulated for a training programme in chairmanship of policy bodies. Although much of the preparatory groundwork may have been carried out by one centre, the need may well emerge for subsequent examination by a policy body, within the funding agency, to discuss and resolve issues about the location and financial support; indeed, the new activity may eventually be provided by a quite separate centre, for reasons which may not always be adequately communicated. Within the centre at which the chairmanship programme is to be offered an idealised model will already have taken shape in the minds of those more directly involved, who will begin to suggest demands for funds, staff, accommodation, practical exercises, secretarial support and so on. Indeed, it is reasonable to assume that at the initial policy formulation stage, in a board or study programme committee meeting, a staff team or individual will be expected to introduce an outline of this model and summarise its essential requirements. The formulation of programme policy emerges from such discussions, where the overall intention is to review possibilities, consider alternative provisions, to question concepts and utilisation of staff and to examine the interface relationships which will need to be established with existing Centre responsibilities. From this stage the provisional tailor-made model begins to be exposed to a diversity of pressures and contraints giving rise either to modifications and, possibly, a more relevant and workable 
model, or to a product substantially different from the idealised form, and whose characteristics demonstrate a closer affinity with the existing organisation pattern and resources than with the potential intake needs whose existence gave substance to the original model. In these circumstances it may prove realistic for the design team to have available alternative models, or variations on a minor theme, to facilitate the decision of the policy body or at least discourage the tendency in committee for support to be generated for what subsequently proves to be a rash or ill-conceived proposal.

In the sequence of events from programme formulation to provision, it may be doubted whether the projected activity can survive in any viable form unless it can remain protected by an accountable staff member or planning team. Some attempt is desirable to achieve a readily practicable synthesis between the organisation policy body and the planning staff, to deter the latter from embarking upon commitments which might prove out-of-gear with accepted policy. It should also enable those staff likely to be looked to for contributions on the new programme to express viewpoints and needs at the formative stages. Moreover, the synthesis should empower the planning team to embark on detailed blue-printing of the programme with some assurance that its efforts, based upon approved policy and resources allocated, will not be frustrated by policy changes-one of the bugbears of the programme director.

Such a predicament will be discouraged by the aprroach implied by R. J. S. Baker's phrase "organic flexibility within a framework of order". 1 This calls for the discreet and functional use of consensus situations, the existence of defined staff responsibilities and a recognisable organisational structure within which the planning staff is afforded opportunity and encouragement for adequate consultation with individual staff. Whether it is necessary to appoint a programme director or manager, and to what extent such a staff member should have access to, or be expected to work through the programme team during detailed programme planning and provision, are not matters on which an overall rationale is explored here; much depends upon the staff members, their experience, expertise, style and context. But it does seem desirable that whatever the control and co-ordination mechanism utilised it must be readily identified by all concerned-staff, intakes, and the organisation. At worst, it can degenerate into a formless expression of staff and programme-

1 Administrative Theory and Public Administration, 1972. intake thoughts and aspirations. By contrast it may become an unduly rigid work matrix on which both intake and staff members are shunted around mechanically along predetermined paths.

Both at the policy stage and in detailed planning, the need will certainly be encountered for specific attention to the essential nature of the progamme. It may not always be accurate or helpful to label it as a training programme, yet if it is substantially educational or conceptual in its orientation this may discourage support from the civil services of developing countries. Either label might attract the individual applicant whose motivation is career advancement. It is not intended to argue here for a clear-cut division between training and education processes, but rather for a commitment to take account of the needs of participants. Are programme staff concerned with the actual work involved in public administration, with the acquisition of identifiable knowledge areas, skills and attitudes which can be reflected in the objectives for the programme? Do intake sponsor organisations seek an end-of-programme assurance that the participants have demonstrated competence in a range of theory and practical tests? Are individual participants looking for a programme leading to a diploma, and if so will this be awarded on the basis of proven ability to select questions which least expose the candidate's inadequacies? Does the programme aim at continuous assessment?

Differing approaches give rise to different emphases. So often disappointment on the part of participants and their sponsors is due to inadequate attention to needs assessment. This defect is coupled with a failure to search out a programme which appears to meet those defined needs. Matching the two involves a close look at existing programmes-not just from brochures or past participants, but where necessary by correspondence or visit. Where new programmes are being planned the staff involved should have access to those in representative sponsoring organisations competent to explain and discuss the various needs assessed; but the results will often be less than satisfactory. One problem confronting public services in the identification of needs is that it is by no means certain that ex-participants will be able to return to those work areas where their newly acquired competences are applicable. This may well encourage support for a generalist public administration programme, although these have often been disappointing to individual participants or their employers.

From these observations it is clear that broadlybased public administration training programmes 
for intakes assembled from diverse overseas services are unlikely to achieve effective training objectives, whether explicit or implicit. A high degree of specificity in programme objectives is required for achievements in training, with demonstrated facilities for the acquisition of the competences defined, within structured conditions. By contrast, the educational opportunities offered to individual civil servants from developing countries to participate in programmes with international compositions are substantial, at least potentialiy, and can be effectively exploited by appropriate design of experience and discussion situations.

At the policy formulation and review stage it will be necessary to examine in some detail the basic concepts of any new proposals in model form, preferably, as indicated, with one or more alternatives. The design team responsible for initiating these models will already have well-developed ideas and convictions about the programme needs, construction and contents, and may have decided upon appropriate study and training methods. They will have given some thought to the sequence of components to achieve programme balance, for example between theory sessions and exercises, and the incidence of visits, attachments and the submission of written work. Unless such clearly evolved ideas are available prior to the policy sessions, which are likely to be attended by a larger number of staff, it is comparatively easy for the policy body to lose sight of real objectives and approve an unsuitable programme. In whatever form the model is approved it must represent an effective compromise between design ideals and organisational constraints. Even more, it needs to be forged from resilient materials if the programme is to remain viable in the vicissitudes which it will face in timetabling.

In the area of public administration study it is particularly desirable that in the design of programmes adequate opportunity be provided for participants to share responsibility for goals identication and other procedures. These can be allocated in syndicate projects, seminars, counselling, and on-going evaluation of programme components. Compromise is of course inevitable in all design work, especially perhaps in public administration studies, where human factors are so important. Recognition of the potential for diverse, and sometimes unpredictable, modification of programmes by contributing staff is essential in the selection and management of staff contributions. A member of staff may be expert in organisation and methods but lifeless in communications skills, whilst another may fill a room with learning aids whose use consumes the attention he should be spending on subject content. These may be exaggerated illustrations, but the choice at the programme director's disposal is limited and new commitments will inevitably be slotted into current obligations. If the manner in which new obligations are assimilated into existing work programmes is left substantially to the individual contributors the blue-print may degenerate: an unmanaged programme is a jungle through which staff will cut their own paths. If staff fail to consult the programme director on changes in contents, methods and procedures then the director must seek alternative ways to ensure that his responsibilities to the programme are not vitiated. Nevertheless, differing interpretations and emphases are bound to be placed by contributors. How far is it justifiable, then, for programme designers or policy bodies to resist changes? Until the model begins to work it is not always possible to envisage its implications; in fact there is good cause for regarding the first year, off the drawing board, as a pilot-scheme and then allowing any resultant revised version to operate for at least two years before any more substantial changes are introduced. Constant change in programme content can be demoralising and confusing; indeed it is difficult to assess the merits or defects of components or programme patterns unless some degree of stability is assured.

Communications are vital links in the programme matrix which will, if used rationally and systematically, induce stability. Whatever system is adopted it will be necessary to include staff, participants, outside support agencies, and sponsoring governments. The need to transmit information emerges variously in pre-programme publicity such as brochure preparation, during induction programmes in the form of detailed handbooks and timetables, during the handling of components and the allocation of responsibilities. Participants will be required to submit analyses in exercises, syndicate reports, studies on field attachments, essays and dissertations. Staff may be required to produce post-programme reports on their components and participant performances. Evaluators, in whatever other capacity they may function-as external assessors, participants, internal staff, programme directors or organisational heads-will need to plan and collect data, apply measures and procedures to provide bases for judgements. In the performance of these functions the details communicated and the format adopted will be determined within the operating environment, reflecting existing procedures in the organisation and also work styles, 
interests, and competences. Not all communications have to be written, neither should they always be formalised although it is essential to realise that for at least one purpose, records, written information is essential. Whilst it is clearly possible to amass quantities of paper which obscure the work and objectives of the programme, some communications form an inescapable and integral component of programmes. Most centres providing progranımes can afford to look closely at the paper products generated and to discover where inadequacies or superfluities exist. It is likely that in two major areas, improvements could be achieved. One is in the subject components which are handled mainly through lecture/discussion type sessions about which less than sufficient detail is made available to staff colleagues or participants, or evaluators. The other is in the record by staff of events, problems, sequences, and observations which can be so valuable in the overall assessment of programmes and without which facts and data are so quickly lost, distorted or displaced by subsequent experiences. Yet however meticulous the preparation, distribution and retention of information, the impact depends upon a soundly structured programme, clearly enunciated in a programme handbook and able to sustain a constructive conformity with established goals.

Brochures have already been mentioned as preliminary agents for the communication of programme data. It is not surprising to discover that some are given only casual, inadequate or biased attention by their originators. Undeniably, questions of presentation, layout and image are significant but in the long-term interests of the programme and of the centre offering it, and recognising the need to reduce the incidence of misfits resulting from faulty selection, the brochure contents must surely be looked to as a reliable guide to contents, objectives and patterns.

Such approaches to communications as indicated may also help the evaluator who so often struggles in a programme environment characterised by vague intentions and implications, rather than by specific objectives and demonstrated events. Evaluation is sometimes conceived as an extraneous operation performed as a concession to institutional traditions, preferably taking place on the last day of a programme and preceded or followed by a ceremonial period of refreshments and camaraderie. One alternative approach is to use an external examiner, who is expected to obtain relevant information on situations subjectively provided by host staff, with inadequate access to data, or working in a rigorously compressed time-scale. Another, all too rare, is to utilise all available sources, human and material, in the pursuit of clearly designed evaluation objectives. Such a target will not be achieved without sustained effort. diligent planning and attenton to detail, together with a disciplined attempt to arrive at judgements based upon facts and pre-established criteria, rather than by ad hocery and post programme rationalisation. Undue emphasis has often been placed upon the reactions of participants, yet the full range of agents should be employed, from whose contributions it will be the demanding task of co-ordinating evaluators to extract and analyse valid data. To illustrate, it would be open perhaps to participants to comment on the organisation of lecture components, but they might be less competent than staff members to make constructive suggestions. It would be equally unreliable to judge the reactions of participants to a lecture series by consulting only its originator. These issues are complex enough, but the primary problem is to establish clearly in the minds of evaluators the precise goal of their activity. Is it to judge the whole course from some abstract standpoint, or to assess the performance of participants in selected events, or to compare the efficacy of different learning methods, say, lecture discussion with incident process case study, or what? So many evaluation studies are time consuming yet profitless because these preliminaries have been overlooked or studiously bypassed. Ultimately no programme can develop predictably and achieve its ends unless it incorporates a process of evaluation. Indeed, it is difficult to imagine a successful study programme which did not, on a continuous basis, require and facilitate the collection of data by staff involved in the work, its organisation and components. It is to be expected that on such a working basis all staff involved will share in the production of regular written evaluation studies, for internal purposes and also for external distribution, even if the latter form is less revealing. 